\title{
Double-Cropping Cucumbers and Squash After Resistant Bell Pepper for Root-Knot Nematode Management
}

Judy A. Thies, Research Plant Pathologist, U.S. Vegetable Laboratory, United States Department of AgricultureAgricultural Research Service (USDA-ARS), Charleston, SC; Richard F. Davis, Research Plant Pathologist, Crop Protection and Management Research Unit, USDA-ARS, Tifton, GA; John D. Mueller, Professor, Clemson University, Edisto Research and Education Center, Blackville, SC; Richard L. Fery, Research Geneticist, U.S. Vegetable Laboratory; David B. Langston, Assistant Professor, Rural Development Center, University of Georgia, Tifton; and Gilbert Miller, Senior County Extension Agent, Bamberg County, SC

\begin{abstract}
Thies, J. A., Davis, R. F., Mueller, J. D., Fery, R. L., Langston, D. B., and Miller, G. 2004. Double-cropping cucumbers and squash after resistant bell pepper for root-knot nematode management. Plant Dis. 88:589-593.

'Charleston Belle', a root-knot nematode-resistant pepper (Capsicum annuит var. апnиит [Grossum Group]), and its susceptible recurrent parent, 'Keystone Resistant Giant', were compared as spring crops for managing the southern root-knot nematode (Meloidogyne incognita) in fall-cropped cucumber (Cucumis sativus) and squash (Cucurbita pepo) at Blackville, SC and Tifton, GA. 'Charleston Belle' exhibited minimal root galling and nematode reproduction, and 'Keystone Resistant Giant' exhibited severe root galling and high nematode reproduction. $\mathrm{Cu}-$ cumber grown in plots following 'Charleston Belle' had lower $(P \leq 0.001)$ root gall severity indices than following 'Keystone Resistant Giant' (4.2 versus 4.9, respectively). Cucumber yields were $87 \%$ heavier $(P \leq 0.0001)$ and numbers of fruit were $85 \%$ higher $(P \leq 0.0001)$ in plots previously planted to 'Charleston Belle' than to 'Keystone Resistant Giant'. Squash grown in plots following 'Charleston Belle' had lower $(P \leq 0.001)$ root gall severity indices than following 'Keystone Resistant Giant' (4.0 versus 4.8, respectively). Squash yields were 55\% heavier $(P \leq 0.01)$ and numbers of fruit were $50 \%$ higher $(P \leq 0.001)$ in plots previously planted to 'Charleston Belle' than to 'Keystone Resistant Giant'. These results demonstrate that root-knot nematode-resistant bell pepper cultivars such as 'Charleston Belle' are useful tools for managing $M$. incognita in double-cropping systems with cucurbit crops.
\end{abstract}

Additional keywords: nematode resistance

The southern root-knot nematode, Meloidogyne incognita (Chitwood) Kofoid and White, is a major limiting factor to pepper and cucurbit production in the United States and worldwide $(2,3,15,19,24)$. In the United States, preplant soil fumigation with methyl bromide is the primary

Corresponding author: J. A. Thies

E-mail: jthies@saa.ars.usda.gov

Technical contribution no. 4390 of Clemson University, Department of Entomology, Soils, and Plant Sciences.

Mention of trade names or commercial products in this article is solely for the purpose of providing specific information and does not imply recommendation or endorsement by the U.S. Department of Agriculture.

Accepted for publication 5 December 2003.

Publication no. D-2004-0331-01R

This article is in the public domain and not copyrightable. It may be freely reprinted with customary crediting of the source. The American Phytopathological Society, 2004. method for controlling root-knot nematodes in high-value vegetable crops (22). Because of the ozone-depleting properties of methyl bromide, its production in the United States will cease by 1 January 2005 (23). Although other soil fumigants and nematicides have varying degrees of usefulness for controlling root-knot nematodes in vegetable crops, environmental concerns and high costs of reregistration may limit use of these pesticides as feasible alternatives to methyl bromide. Thus, there is a great deal of interest in development of alternative methods for managing root-knot nematodes in vegetable crops. One approach would be the utilization of root-knot nematode-resistant vegetable cultivars as rotational crops to limit damage caused by root-knot nematodes in subsequent susceptible vegetable crops. In Louisiana, 'Dasher II' cucumber doublecropped after the root-knot nematoderesistant 'Celebrity' tomato produced heavier yields of marketable fruit and had less severe root-galling and lower population densities of second-stage juveniles of $M$. incognita in the soil than the same cucumber cultivar grown after the susceptible 'Heatwave' tomato (1,7). Muskmelons double-cropped after 'Celebrity' tomato also exhibited less severe root-galling and produced heavier yields than muskmelons grown after 'Heatwave' tomato (6).

The U. S. Vegetable Laboratory, United States Department of Agriculture-Agricultural Research Service (USDA-ARS), Charleston, SC, released the root-knot nematode-resistant bell pepper cv. Charleston Belle in 1997 (5). This open-pollinated cultivar is homozygous for the dominant $N$ gene that controls resistance to $M$. incognita (5), $M$. arenaria races 1 and 2, and $M$. javanica (17). 'Keystone Resistant Giant' is the susceptible recurrent parental cultivar used in the backcross breeding procedure (six backcrosses) to develop 'Charleston Belle' (5). The reactions of 'Charleston Belle' and its near-isogenic parent, 'Keystone Resistant Giant', to rootknot nematodes have been characterized in greenhouse and growth-chamber environments $(16,17)$, but there is little information available on the use of resistant bell pepper cultivars in double-cropping systems with susceptible vegetable crops. The objective of these studies was to determine the potential of using a resistant bell pepper cultivar as a rotation crop for managing root-knot nematodes in double-cropped cucumber and squash. A secondary objective was to evaluate the effectiveness of resistance to the southern root-knot nematode conditioned by the $N$ gene in 'Charleston Belle' in field tests in South Carolina and Georgia.

\section{MATERIALS AND METHODS}

These studies were conducted at the Clemson University Edisto Research and Education Center, Blackville, SC and the Crop Protection and Management Research Unit, USDA-ARS, Tifton, GA. Two double-crop pepper and cucurbit experiments were conducted at each site. Bell peppers were planted in the spring, followed by a fall crop of either cucumber or yellow squash. The pepper genotypes used 
in these studies were a set of near-isogenic bell pepper cultivars, Charleston Belle $(N N)$ and Keystone Resistant Giant (nn), that differ in resistance to root-knot nematodes controlled by the $N$ gene. The cucumber and squash cultivars used in all experiments were Stonewall and Cougar, respectively.

Egg inocula. Egg inocula of $M$. incognita race 3 were maintained on tomato (Lycopersicon esculentum Mill. cv. Rutgers) and pole bean (Phaseolus vulgaris L. cv. Kentucky Wonder 191) in isolated greenhouse benches. $M$. incognita egg inocula were extracted from infected tomato and bean roots using $0.5 \% \mathrm{NaOCl}(9)$.

Bell pepper-cucumber double-crop study at Blackville, SC. Seed of both bell pepper cultivars were planted in the greenhouse on 30 March 2002. On 3 May 2002, the field was tilled and beds were formed and covered with 3-ml black plastic. On 6 May 2002, the pepper seedlings were inoculated with approximately 5,000 $\mathrm{M}$. incognita race 3 eggs per seedling and, on 8 May 2002, the seedlings were trans- planted into single-row plots on beds $2 \mathrm{~m}$ apart. Each plot contained 25 plants spaced $30 \mathrm{~cm}$ apart. The experimental design was a randomized complete block with 10 replications. At planting, eight cores of soil 20 $\mathrm{cm}$ deep were collected from each plot and combined into a composite sample. Second-stage juveniles (J2) were extracted from $113 \mathrm{~cm}^{3}$ of soil from the composite sample using the sugar flotation method (11).

Standard cultural and insect control practices were followed and plots were subsurface drip irrigated. Soil temperatures were recorded at 10-min intervals at $5-\mathrm{cm}$ and $15-\mathrm{cm}$ depths in the row from 4 June through 17 October 2002. Fruit were harvested from 10 plants in the center of each plot on 17 and 30 July 2002. On 30 July 2002, the root systems and surrounding soil of six pepper plants (fourth through ninth planting positions from the front of the plot) were dug from each plot. The roots were removed carefully from the soil and the soil samples were saved for extraction of $\mathbf{J} 2$. The roots were washed and

Table 1. Gall index, numbers of Meloidogyne incognita eggs per gram of fresh root, second-stage juveniles (J2) per $100 \mathrm{~cm}^{3}$ of soil, total fruit yield, and total fruit numbers of bell pepper cvs. Charleston Belle (CB) and Keystone Resistant Giant (KRG) ${ }^{\mathrm{a}}$

\begin{tabular}{lllccc}
\hline Cultivar $^{\mathbf{b}}$ & Gall index $^{\mathbf{c}}$ & Eggs $^{\mathbf{d}}$ & $\mathbf{J 2}^{\mathbf{d}}$ & Yield (kg/plot) & No. of fruit \\
\hline Blackville, SC & & & & & \\
CB & $1.4^{* * * *}$ & $725^{* * * *}$ & $8^{*}$ & $2.6^{*}$ & $48^{*}$ \\
KRG & 4.6 & 9,515 & 20 & 1.7 & 31 \\
Tifton, GA & & & & & \\
CB & $1.3^{* * * *}$ & $2,424^{* * * *}$ & $16^{* * *}$ & 2.2 & 41 \\
KRG & 3.9 & 11,632 & 225 & 1.6 & 29 \\
Combined & & & & & \\
CB & $1.3^{*} * * *$ & $1,574^{* * * *}$ & $12^{* * * *}$ & $2.4 * *$ & $44^{* * * *}$ \\
KRG & 4.3 & 10,573 & 122 & 1.7 & 30 \\
\hline
\end{tabular}

${ }^{a}$ According to the $F$ test, $*, * *, * * *$, and $* * * *=$ significant at $P<0.05,0.01,0.001$, and 0.0001 , respectively.

b 'Charleston Belle' is resistant and 'Keystone Resistant Giant' is susceptible to M. incognita.

${ }^{\mathrm{c}}$ Gall index: $1=0$ to $3 \%, 2=4$ to $25 \%, 3=26$ to $50 \%, 4=51$ to $79 \%$, and $5=80$ to $100 \%$ root system galled.

${ }^{\mathrm{d}}$ Data were $\log _{10}(x+1)$ transformed before analysis.

${ }^{\mathrm{e}}$ Combined analysis of both tests.

Table 2. Gall index, numbers of Meloidogyne incognita eggs per gram of fresh root, second-stage juveniles (J2) per $100 \mathrm{~cm}^{3}$ of soil, total fruit yield, and total fruit numbers of cucumber cv. Stonewall double-cropped after bell pepper cvs. Charleston Belle (CB) and Keystone Resistant Giant (KRG) ${ }^{\mathrm{a}}$

\begin{tabular}{|c|c|c|c|c|c|}
\hline $\begin{array}{l}\text { Previous } \\
\text { cultivar }^{b}\end{array}$ & Gall index & Eggs $^{d}$ & $\mathrm{J2}^{\mathrm{d}}$ & $\begin{array}{c}\text { Yield } \\
\text { (kg/plot) }\end{array}$ & No. of fruit \\
\hline \multicolumn{6}{|c|}{ Blackville, SC } \\
\hline $\mathrm{CB}$ & $3.5 * * *$ & 3,970 & 645 & $5.8 * * * *$ & $19 * * *$ \\
\hline KRG & 4.9 & 7,346 & 1,190 & 0.7 & 2 \\
\hline \multicolumn{6}{|c|}{ Tifton, GA } \\
\hline $\mathrm{CB}$ & 4.9 & $6,651 *$ & 293 & $4.9 * * *$ & $22 * * *$ \\
\hline KRG & 5.0 & 11,749 & 151 & 0.7 & 3 \\
\hline \multicolumn{6}{|l|}{ Combined $^{\mathrm{e}}$} \\
\hline $\mathrm{CB}$ & $4.2 * * * *$ & $5,310 * * *$ & 469 & $5.3 * * * *$ & $20 * * * *$ \\
\hline KRG & 4.9 & 9,548 & 671 & 0.7 & 3 \\
\hline
\end{tabular}

${ }^{a}$ According to the $F$ test, *, **,***, and $* * * *=$ significant at $P<0.05,0.01,0.001$, and 0.0001 , respectively.

b 'Charleston Belle' is resistant and 'Keystone Resistant Giant' is susceptible to M. incognita.

${ }^{\mathrm{c}}$ Gall index: $1=0$ to $3 \%, 2=4$ to $25 \%, 3=26$ to $50 \%, 4=51$ to $79 \%$, and $5=80$ to $100 \%$ root system galled.

${ }^{\mathrm{d}}$ Data were $\log _{10}(x+1)$ transformed before analysis.

e Combined analysis of both tests. rated for gall severity and egg mass production using a scale of 1 to 5 , where $1=0$ to $3 \%$ root system galled or covered with egg masses; $2=4$ to $25 \%, 3=26$ to $50 \%$, $4=51$ to $79 \%$, and $5=\geq 80 \%$ root system galled or covered with egg masses (20). $M$. incognita eggs were extracted from a bulked 20-g subsample of roots from each plot using $1 \% \mathrm{NaOCl}$ (9). J2 were extracted from $113 \mathrm{~cm}^{3}$ of soil as previously described. On 31 July 2002, the pepper plants remaining in the plots were sprayed with glyphosate. On 5 August 2002, the shoots of the pepper plants were clipped at the crown and removed, and the black plastic was sprayed with whitewash to increase the reflectivity of the plastic mulch.

On 8 August 2002, two seed of 'Stonewall' cucumber were direct seeded into each hole that previously had been planted with a bell pepper plant. After seedling emergence, seedlings were thinned to one per hill. Standard cultural and pest control practices were followed and plots were subsurface drip irrigated. Fruit were harvested from 10 plants (plant positions 10 through 19 from the front of the plot) in the center of each plot on 26 September and $1,3,8$, and 17 October 2002. On 17 October 2002, the root systems and surrounding soil of 10 cucumber plants were dug from the center of each plot. The roots were removed carefully from the soil and the soil samples were saved for extraction of $\mathbf{J} 2$. The roots were washed and rated for gall severity and egg mass production using a scale of 1 to 5 , as previously described. M. incognita eggs were extracted from a bulked 20-g subsample of roots from each plot using $1 \% \mathrm{NaOCl}$ (9). J2 of $M$. incognita were extracted from $113 \mathrm{~cm}^{3}$ of soil as previously described.

Bell pepper-squash double-crop study at Blackville, SC. The bell pepper and squash experiments were conducted as described for the bell pepper-cucumber study at Blackville, SC. Planting, harvesting, and sampling dates for bell pepper were the same as previously described. Seed of 'Cougar' yellow squash were sown on 8 August 2002. Squash fruit were harvested on 17, 23, and 26 September and 1 and 3 October 2002. On 3 October 2002, soil and root samples were collected, roots were evaluated for severity of galling, and $M$. incognita eggs and $\mathrm{J} 2$ were extracted from roots and soil, respectively, as previously described.

Bell pepper-cucumber double-crop study at Tifton, GA. Field and bed preparation, cultural practices, and experimental design were as described for the Blackville study. Seed of peppers were sown in the greenhouse on 31 March 2002 and transplanted to the field on 29 April 2002. At planting and on 12 August, soil samples were collected and $M$. incognita $\mathrm{J} 2$ were extracted as previously described. Fruit were harvested from all plants in each plot 
on 24 July and 12 August 2002. 0n 14 August 2002, the root systems of six plants were dug from the center of each plot. Roots were rated for gall severity and eggs were extracted from $20 \mathrm{~g}$ of fibrous roots as previously described. The plots were treated as previously described in preparation for the fall cucumber crop.

Sowing and culture of cucumber were as previously described. On 22 August 2002, seed of 'Stonewall' cucumber were sown. Fruit were harvested from 10 cucumber plants in the center of each plot on 9,11 , $15,18,21,25$, and 28 October and 1 and 4 November 2002. On 4 November 2002, soil samples were collected, root systems of 10 cucumber plants were dug, and roots were rated for gall severity. $M$. incognita $\mathrm{J} 2$ and eggs were extracted from soil and root samples, respectively, as previously described.

Bell pepper-squash double-crop study at Tifton, GA. The bell peppersquash experiment was conducted as described for the bell pepper-cucumber study at Tifton, GA. Planting, harvesting, and sampling dates for bell pepper were the same. On 22 August 2002, seed of 'Cougar' yellow squash were sown. Fruit were harvested on $3,9,11,15$, and 18 October 2002. On 29 October 2002, root samples were collected and evaluated for root gall severity, and $M$. incognita eggs were extracted and counted. On 13 November 2002, 10 cores of soil were collected from each plot and J2 were extracted as previously described.

Data analysis. Nematode egg and J2 data were $\log _{10}(x+1)$ transformed to normalize the error variance before analysis (14). Data were analyzed using the GLM procedure of SAS for Windows (version 6.12; SAS Institute, Cary, NC).

\section{RESULTS}

Bell pepper-cucumber double-crop study at Blackville, SC. Density of $M$. incognita $\mathrm{J} 2$ was approximately 10 per 100 $\mathrm{cm}^{3}$ of soil at planting. Soil temperatures ranged from 13.4 to $43.0^{\circ} \mathrm{C}$ at a $5-\mathrm{cm}$ depth and from 16.0 to $38.3^{\circ} \mathrm{C}$ at a $15-\mathrm{cm}$ depth from 4 June to 17 October 2002. Because bell pepper data for the cucumber and squash experiments at Blackville, SC were not significantly different and there were no interactions between the two studies, the bell pepper data were combined for analysis (Table 1). The resistant cv. Charleston Belle had a root gall severity index of 1.4 and the root systems supported $725 \mathrm{M}$. incognita eggs per gram of fresh root (Table 1). In contrast, the susceptible cv. Keystone Resistant Giant had a root gall severity index of 4.6 and the root systems supported 9,515 M. incognita eggs per gram of fresh root. 'Charleston Belle' had $92 \%$ fewer $(P<0.0001)$ eggs per gram of fresh root than its susceptible isoline 'Keystone Resistant Giant'. There were $60 \%$ fewer $(P<0.05) \mathrm{J} 2$ in the soil at the last harvest in plots where 'Charleston Belle' had been grown than in plots where 'Keystone Resistant Giant' had been grown. 'Charleston Belle' produced 1.5x greater $(P \leq 0.05)$ numbers of fruit and fruit yield than 'Keystone Resistant Giant'.

Cucumber plants grown in plots following the resistant cv. Charleston Belle had less severe root galling $(P \leq 0.001)$ than those following the susceptible 'Keystone Resistant Giant' (gall indices were 3.5 versus 4.9, respectively; Table 2; Fig. 1A and B). Cucumber yields were $87 \%$ heavier $(P$ $\leq 0.0001)$ and numbers of fruit were $89 \%$ higher $(P \leq 0.001)$ in plots previously planted to 'Charleston Belle' than to 'Keystone Resistant Giant'.
Bell pepper-cucumber double-crop study at Tifton, GA. Density of $M$. incognita $\mathrm{J} 2$ was approximately 119 per $100 \mathrm{~cm}^{3}$ of soil at planting. Bell pepper data for the cucumber and squash experiments at Tifton, GA were not significantly different and there were no interactions between the two studies; therefore, the bell pepper data were combined for analysis (Table 1). 'Charleston Belle' had a root gall severity index of 1.3 and the root systems supported 2,424 M. incognita eggs per gram of fresh root (Table 1). 'Keystone Resistant Giant' had a root gall severity index of 3.9 and root systems supported 11,632 $M$. incognita eggs per gram of fresh root 'Charleston Belle' had $79 \%$ fewer $(P \leq$
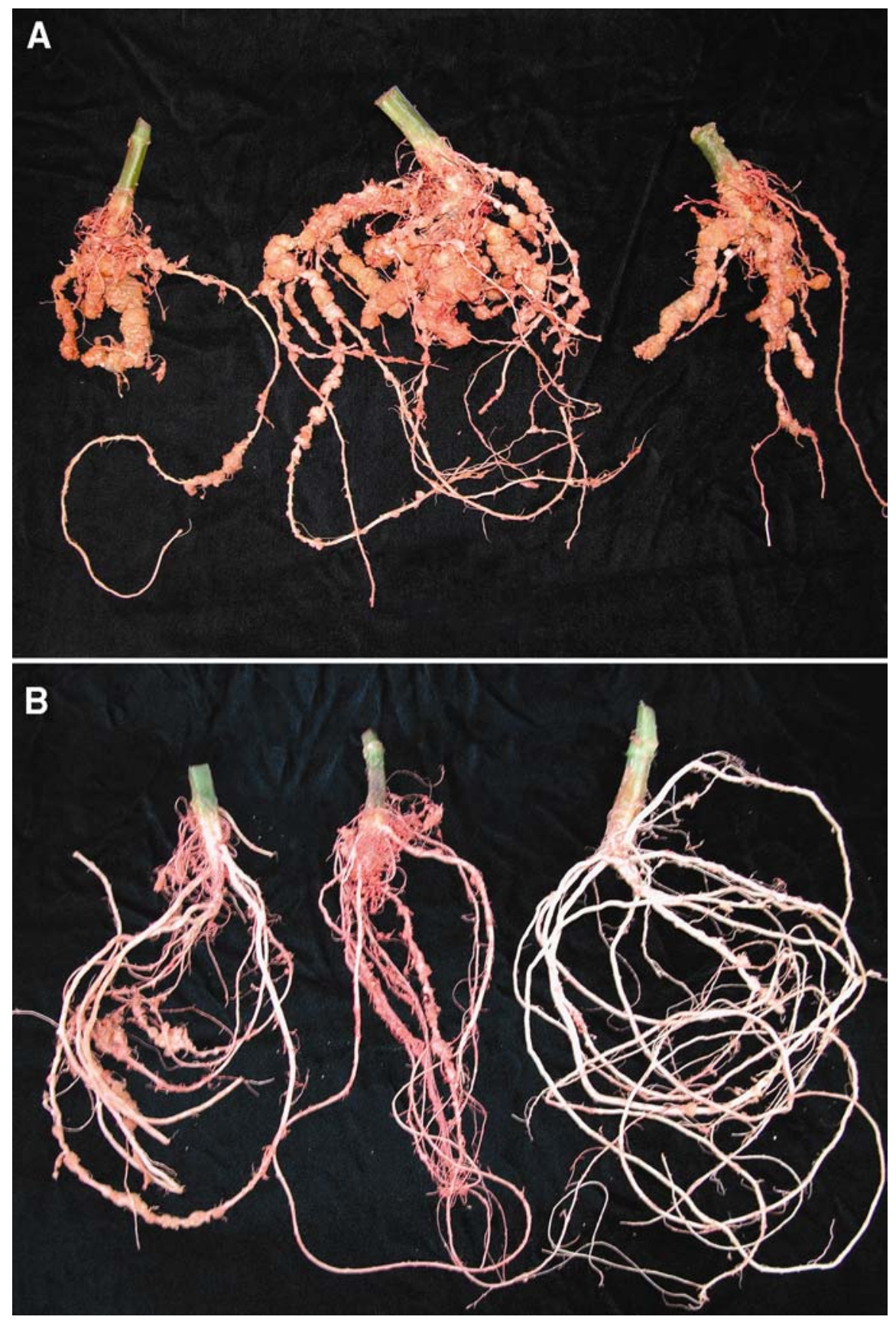

Fig. 1. A, Roots of 'Stonewall' cucumber grown in a double-crop sequence following the root-knot nematode-susceptible bell pepper 'Keystone Resistant Giant', and B, roots of 'Stonewall' cucumber following the root-knot nematode-resistant bell pepper 'Charleston Belle', in Blackville, SC. 
$0.0001)$ eggs per gram of fresh root and $92 \%$ fewer $(P \leq 0.001) \mathrm{J} 2$ in the soil at the final harvest than 'Keystone Resistant Giant'.

Cucumber plants grown in plots previously planted to the resistant cv. Charleston Belle had $43 \%$ fewer $(P \leq 0.05) M$. incognita eggs per gram of fresh root than those planted to 'Keystone Resistant Giant' (Table 2). Cucumber yields were $86 \%$ heavier $(P \leq 0.001)$ and numbers of fruit were $86 \%$ higher $(P \leq 0.001)$ in plots previously planted to 'Charleston Belle' than to 'Keystone Resistant Giant'.

Bell pepper-squash double-crop study at Blackville, SC. Bell pepper results were presented previously (see bell pepper-cucumber double-crop study at Blackville, SC). The root gall severity was less $(P \leq 0.001$; Table 3; Fig. 2) and $M$. incognita egg production was $59 \%$ less $(P$ $\leq 0.05$ ) for squash following 'Charleston Belle' than those grown after 'Keystone Resistant Giant'. Likewise, numbers of J2 in the soil were $66 \%$ less $(P \leq 0.01)$ in plots where squash followed 'Charleston Belle' compared with plots where squash followed 'Keystone Resistant Giant'. Squash yields were $54 \%$ heavier $(P \leq 0.05)$ and numbers of squash fruit were $45 \%$ higher $(P \leq 0.01)$ when grown following 'Charleston Belle' compared with 'Keystone Resistant Giant'.

Bell pepper-squash double-crop study at Tifton, GA. Bell pepper results were presented previously (see bell pepper-cucumber double-crop study at Tifton, GA). The root gall severity index and $M$.

Table 3. Gall index, numbers of Meloidogyne incognita eggs per gram of fresh root, second-stage juveniles (J2) per $100 \mathrm{~cm}^{3}$ of soil, total fruit yield, and total fruit numbers of squash cv. Cougar double-cropped after bell pepper cvs. Charleston Belle (CB) and Keystone Resistant Giant (KRG) ${ }^{\mathrm{a}}$

\begin{tabular}{lllccc}
\hline $\begin{array}{l}\text { Previous } \\
\text { cultivar }^{\mathbf{b}}\end{array}$ & Gall index $^{\mathbf{c}}$ & Eggs $^{\mathbf{d}}$ & $\mathbf{J 2}^{\mathbf{d}}$ & $\begin{array}{c}\text { Yield } \\
(\mathbf{k g} / \mathbf{p l o t})\end{array}$ & No. of fruit \\
\hline $\begin{array}{l}\text { Blackville, SC } \\
\text { CB }\end{array}$ & $3.3^{* * *}$ & $10,710^{*}$ & $686^{* *}$ & $3.5^{*}$ & $22^{* *}$ \\
KRG & 4.7 & 26,418 & 2,004 & 1.6 & 12 \\
Tifton, GA & & & & & \\
CB & 4.6 & 13,020 & 248 & $1.7^{*}$ & $10^{*}$ \\
KRG & 4.9 & 15,444 & 306 & 0.7 & 4 \\
Combined & & & & & \\
CB & $4.0^{* * * *}$ & $11,865^{*}$ & $467^{* *}$ & $2.7^{* *}$ & $16^{* * *}$ \\
KRG & 4.8 & 20,931 & 1,155 & 1.2 & 8 \\
\hline
\end{tabular}

a According to the $F$ test, *, **, ***, and $* * * *=$ significant at $P<0.05,0.01,0.001$, and 0.0001 , respectively.

b 'Charleston Belle' is resistant and 'Keystone Resistant Giant' is susceptible to $M$. incognita.

${ }^{\mathrm{c}}$ Gall index: $1=0$ to $3 \%, 2=4$ to $25 \%, 3=26$ to $50 \%, 4=51$ to $79 \%$, and $5=80$ to $100 \%$ root system galled.

${ }^{\mathrm{d}}$ Data were $\log _{10}(x+1)$ transformed before analysis.

${ }^{\mathrm{e}}$ Combined analysis of both tests.

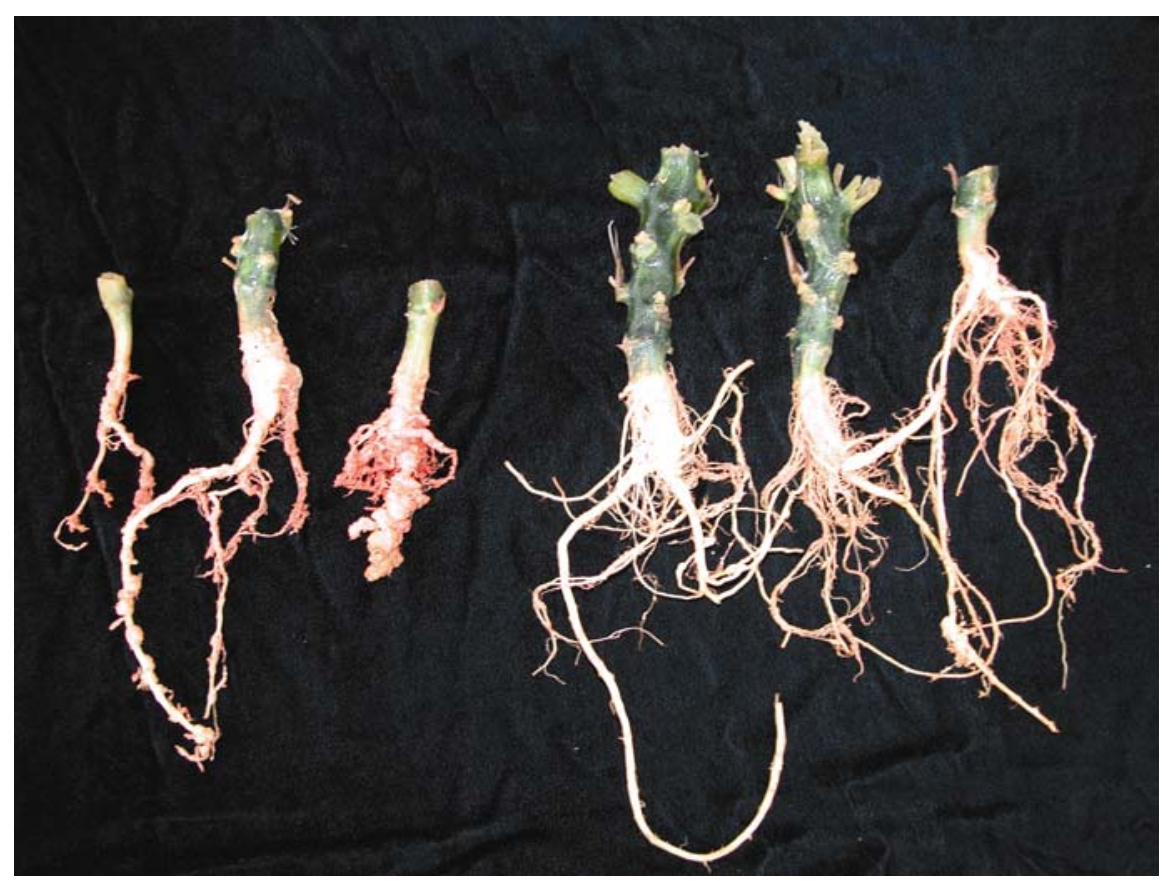

Fig. 2. Roots of 'Cougar' yellow squash plants grown in a double-crop sequence following the rootknot nematode-susceptible bell pepper 'Keystone Resistant Giant' (left) and following the root-knot nematode-resistant bell pepper 'Charleston Belle'(right), in Blackville, SC. incognita egg production on squash plants grown after 'Charleston Belle' were not significantly different from those grown after 'Keystone Resistant Giant' (Table 3). Squash yields were $59 \%$ heavier $(P \leq 0.05)$ and numbers of squash fruit were $60 \%$ higher $(P \leq 0.05)$ when grown in plots following 'Charleston Belle' compared with 'Keystone Resistant Giant'.

\section{DISCUSSION}

'Charleston Belle' exhibited a high level of resistance and 'Keystone Resistant Giant' was susceptible in both the Blackville, SC and Tifton, GA studies, confirming results of previous experiments in which root galling and reproduction of $M$. incognita were minimal on 'Charleston Belle' and root galling was severe and reproduction of M. incognita was high on 'Keystone Resistant Giant' $(16,17)$. 'Charleston Belle' $(N N)$ produced significantly greater fruit yield than its susceptible near-isoline 'Keystone Resistant Giant' ( $n n)$ in the Blackville study, similar to results of another study conducted at Blackville, SC in 2001 (21). In prior trials, the resistant 'Carolina Cayenne' pepper, which also is homozygous for the $N$ gene and carries an additional recessive gene that confers resistance to $M$. incognita, produced significantly greater yields than its susceptible near-isoline PA-136 when grown in $M$. incognita-infested fields (19). Results of the present and previous studies demonstrate the effectiveness of the $N$ gene in controlling the southern root-knot nematode in field-grown pepper $(19,21)$.

Breakdown of resistance to $M$. incognita under high soil temperatures has been reported in several horticultural crop species, including tomato, bean, and sweet potato $(4,8,10,13)$. Resistance breaking due to high soil temperatures has been reported in both bell pepper ( $C$. annuum) and in Scotch Bonnet-type peppers $(C$. chinense) in controlled environment studies $(16,18)$. Although the resistant bell cvs. Charleston Belle and Carolina Wonder exhibited a partial loss of resistance at 28 and $32^{\circ} \mathrm{C}$, reproduction of $M$. incognita on these cultivars was only $20 \%$ of that on the susceptible parental cvs. Keystone Resistant Giant and Yolo Wonder B, respectively, and root gall indices of the resistant cultivars were still within the moderately resistant range (16). Because the majority of bell peppers grown in the United States are produced in hot climates, knowledge of the heat stability of root-knot nematode resistance is critical both in the development of pepper cultivars and in making recommendations about nematode management to pepper growers. Results of the present study demonstrate that resistance exhibited by 'Charleston Belle' is effective even under the high soil temperatures recorded in the Blackville, SC study, in which maximum daily temperatures ranged from 25.7 to $38.3^{\circ} \mathrm{C}$ at a $15-\mathrm{cm}$ soil 
depth. Thus, it appears that resistance conditioned by the $N$ gene was stable at the high soil temperatures in the present study, even though resistance of 'Charleston Belle' was partially lost at constant soil temperatures of 28 and $32^{\circ} \mathrm{C}$ in controlled environment experiments (16). A possible explanation for the differences in response of 'Charleston Belle' under field and controlled environment conditions is that soil temperatures fluctuated during the course of $24 \mathrm{~h}$ in the plastic mulched pepper beds, whereas the soil temperature in the growth chamber was relatively stable at $32^{\circ} \mathrm{C}$, which provided the conditions necessary for a partial loss of resistance in 'Charleston Belle'.

'Stonewall' cucumber plants grown in plots following 'Charleston Belle' had less severe root galling and $44 \%$ fewer eggs per gram of fresh root than cucumber plants grown after 'Keystone Resistant Giant' (averaged over both locations). Cucumber fruit yields (averaged over both locations) were $87 \%$ greater in plots following 'Charleston Belle' than in plots following 'Keystone Resistant Giant'. These results are similar to those reported from Louisiana in which 'Dasher II' cucumber doublecropped following the root-knot nematoderesistant 'Celebrity' tomato produced heavier yields, had reduced root-galling, and lower densities of $M$. incognita $\mathrm{J} 2$ in the soil than the same cultivar grown after the susceptible 'Heatwave' tomato $(1,7)$.

In the present studies, 'Cougar' squash plants grown following 'Charleston Belle' pepper had less severe root galling, $43 \%$ fewer eggs per gram of fresh root, and $60 \%$ fewer $\mathrm{J} 2$ present in the soil at the final harvest than squash plants grown following 'Keystone Resistant Giant' pepper (averaged over both locations). Fruit yields of squash grown following 'Charleston Belle' (averaged over both locations) were $55 \%$ greater than fruit yields of squash grown following 'Keystone Resistant Giant'. In another double-crop study conducted in Tifton, GA, soil populations of $M$. incognita recovered in 'Charleston Belle' plots were about $11 \%$ of those recovered in the susceptible bell pepper 'Camelot' plots (24). Fruit weights of 'Dixie' squash grown after 'Charleston Belle' and after 'Camelot' bell peppers were not different. In Florida, yield of 'Lemondrop' squash grown in the spring following the previous summer's rotation crop of 'Hale' castor, 'Deltapine 90' cotton, velvetbean, or crotalaria produced heavier yields than squash grown after root-knot nematode-susceptible 'Florunner' peanut (12). Root-gall severity ratings of squash grown after any of the abovementioned crops (root-gall severity ratings ranged from 3.7 to 4.8 using a 1-to-5 rating scale) were not different.

Our results demonstrated the effectiveness of resistance to the southern root-knot nematode conditioned by the $N$ gene in 'Charleston Belle' pepper under field conditions in South Carolina and Georgia. Furthermore, the present studies showed that root-knot nematode-resistant bell pepper cultivars, such as Charleston Belle, will be useful tools for managing $M$. incognita in double-cropping systems with cucurbit crops. The utilization of resistant vegetable cultivars will provide economical and environmentally compatible alternatives to methyl bromide and other nematicides for managing $M$. incognita in vegetable crops. An integrated pest management approach that utilizes other nematode management techniques, such as biocontrol organisms or resistant cover crops, in combination with root-knot nematode-resistant pepper may be necessary in order to achieve acceptable yields of highly susceptible cucurbits in a double-crop production scheme.

\section{ACKNOWLEDGMENTS}

We thank S. B. Merrill, P. Berland, J. Carey, T. Hilton, and A. K. Montfort for technical assistance in conducting the experiments.

\section{LITERATURE CITED}

1. Colyer, P. D., Kirkpatrick, T. L, Vernon, P. R., Barham, J. D., and Bateman, R. J. 1998. Reducing Meloidogyne incognita injury to cucumber in a tomato-cucumber double-cropping system. J. Nematol. 30:226-231

2. Di Vito, M., Cianciotta, V., and Zaccheo, G. 1992. Yield of susceptible and resistant pepper in microplots infested with Meloidogyne incognita. Nematropica 22:1-6.

3. Di Vito, M., Greco, N., and Carella, A. 1985. Population densities of Meloidogyne incognita and yield of Capsicum annuum. J. Nematol. $17: 45-49$.

4. Dropkin, V. H. 1969. The necrotic reaction of tomatoes and other hosts resistant to Meloidogyne: Reversal by temperature. Phytopathology 59:1632-1637.

5. Fery, R. L., Dukes, P. D., Sr., and Thies, J. A. 1998. 'Carolina Wonder' and 'Charleston Belle': Southern root-knot nematode resistant bell peppers. HortScience 33:900-902.

6. Hanna, H. Y. 2000. Double-cropping muskmelons with nematode-resistant tomatoes increases yield, but mulch color has no effect. HortScience 35:1213-1214.

7. Hanna, H. Y., Colyer, P. D., Kirkpatrick, T. L., Romaine, D. J., and Vernon, P. R. 1994. Feasibility of improving cucumber yield without chemical control in soils susceptible to nematode build-up. HortScience 29:1136-1138.

8. Holtzmann, O. V. 1965. Effect of soil temperature on resistance of tomato to root-knot nematode (Meloidogyne incognita). Phytopathology 55:990-992.

9. Hussey, R. S., and Barker, K. R. 1973. A comparison of methods of collecting inocula of
Meloidogyne spp., including a new technique. Plant Dis. Rep. 57:1025-1028.

10. Jatala, P., and Russell, C. C. 1972. Nature of sweet potato resistance to Meloidogyne incognita and the effects of temperature on parasitism. J. Nematol. 4:1-7.

11. Jenkins, W. R. 1964. A rapid centrifugal-flotation technique for separating nematodes from soil. Plant Dis. Rep. 48:692.

12. McSorley, R., Dickson, D. W., de Brito, J. A., Hewlett, T. E., and Frederick, J. J. 1994. Effects of tropical rotation crops on Meloidogyne arenaria population densities and vegetable yields in microplots. J. Nematol. 26:175-181.

13. Mullin, B. A., Abawi, G. S., and Pastor-Corrales, M A. 1991. Modification of resistance expression of Phaseolus vulgaris to Meloidogyne incognita by elevated soil temperatures. J. Nematol. 23:182-187.

14. Noe, J. P. 1985. Analysis and interpretation of data from nematological experiments. Pages 187-196 in: An Advanced Treatise on Meloidogyne. Vol. II: Methodology. K. R. Barker, C. C. Carter, and J. N. Sasser, eds. North Carolina State University Graphics, Raleigh.

15. Sasser, J. N., and Freckman, D. W. 1987. A world perspective on nematology: The role of the society. Pages 7-14 in: Vistas on Nematology: A Commemoration of the Twenty-Fifth Anniversary of the Society of Nematologists. J. A. Veech and D. W. Dickson, eds. Society of Nematology, Hyattsville, MD.

16. Thies, J. A., and Fery, R. L. 1998. Modified expression of the $N$ gene for southern rootknot nematode resistance in pepper at high soil temperatures. J. Am. Soc. Hortic. Sci. 123:1012-1015

17. Thies, J. A., and Fery, R. L. 2000. Characterization of resistance conferred by the $N$ gene to Meloidogyne arenaria races 1 and 2, M. hapla, and $M$. javanica in two sets of isogenic lines of Capsicum annuum L. J. Am. Soc. Hortic. Sci. 125:71-75.

18. Thies, J. A., and Fery, R. L. 2000. Heat stability of resistance to Meloidogyne incognita in Scotch Bonnet peppers (Capsicum chinense Jacq.). J. Nematol. 32:356-361.

19. Thies, J. A., Mueller, J. D., and Fery, R. L. 1997. Effectiveness of resistance to southern root-knot nematode in 'Carolina Cayenne' pepper in greenhouse, microplot, and field tests. J. Am. Soc. Hortic. Sci. 122:200-204.

20. Thies, J. A., Mueller, J. D., and Fery, R. L. 1998. Use of a resistant pepper as a rotational crop to manage southern root-knot nematode. HortScience 33:716-718.

21. Thies, J. A., Mueller, J. D., Fery, R. L., Miller, G., and Varn, J. E. 2003. Response of bell pepper cultivars near-isogenic for the $N$ gene to Meloidogyne incognita in field trials. HortScience. 38:1394-1396.

22. U.S. Department of Agriculture. 1993. Alternatives to methyl bromide: Assessments of research needs and priorities. Proc. USDA Workshop on Alternatives to Methyl Bromide, Arlington, VA.

23. U.S. Environmental Protection Agency. 2000. Protection of Stratospheric Ozone: Incorporation of Clean Air Act Amendments for Reductions in Class I, Group VI Controlled Substances. Federal Register 65 (No. 229):70795-70804.

24. Webster, T. M., Csinos, A. S., Johnson, A. W., Dowler, C. C., Sumner, D. R., and Fery, R. L. 2001. Methyl bromide alternatives in a bell pepper-squash rotation. Crop Prot. 20:605-614. 